\title{
Análise da Precipitação da Microrregião do Cariri Oriental Paraibano
}

\author{
Analysis of the precipitation of the Microregion of the Oriental Cariri Paraibano
}

\author{
SILVA, G. S.; SILVA, W. S.; SILVA, A. L.; ALMEIDA, N. V.; ARAÚJO, L. E. \\ gyo.vanne@hotmail.com;
}

\section{Resumo}

A região do Nordeste brasileiro (NEB) tem como particularidade grande irregularidade na precipitação, sendo seu comportamento decorrente de um conjunto de fatores, bem como: suas características fisiográficas onde são influenciados por vários sistemas atmosféricos, fenômenos estes transientes. O presente trabalho tem como objetivo principal analisar a variabilidade climática da microrregião do Cariri Oriental Paraibano, onde sua área de estudo é a microrregião do Cariri Oriental localizada no Estado da Paraíba. Os dados pluviométricos foram fornecidos pela AESA (Agência Executiva de Gestão das Águas do Estado da Paraíba) para o cálculo do Índice de Anomalia de Chuva (IAC). Sendo que a climatologia temporal da precipitação da microrregião do Cariri Oriental mostrar-se que seu período chuvoso tem inicio no mês de janeiro e término no mês de julho, em contrapartida o período seco ocorre entre os meses de agosto a dezembro, sendo setembro como o mês mais seco. Para melhor estimar a variabilidade espacial da precipitação empregou-se o Índice de Anomalia de Chuva (IAC), no intuito de melhor identificar a intensidade e duração dos períodos secos e úmidos para série histórica da precipitação.

\section{Palavras chaves}

Índice de Anomalia de Chuva (IAC), Período Seco, Período Chuvoso.

\begin{abstract}
The Northeast Brazilian region (NEB) is characterized by a great irregularity in precipitation, its behavior being due to a set of factors, as well as its physiographic characteristics where they are influenced by several atmospheric systems, phenomena these transients. The presents work has objective is to analyze the climatic variability of the Cariri Oriental Paraibano micro region, where its area of study is the Cariri Oriental micro region located in the State of Paraíba. Rainfall data were provided by the AESA (Paraíba State Water Management Executive Agency) for the calculation of the Rainy Anomaly Index (IAC). Being that the climatology of precipitation of the microregion of the Cariri region show that their rainy season starts in the month of January and ending in the month of July, on the other hand the dry period occurs between the months of August to December, and September as the Month more dry. In contrast, the dry period occurs between August and December, September being the month driest. To better estimate a spatial variability of precipitation, the Rainfall Anomaly Index (IAC), In order to better identify the intensity and duration of the dry and humid periods for the historical series of precipitation.
\end{abstract}

\section{Keywords}

Rain Anomaly Index (IAC), Period Dry, Period Rainy. 


\section{Introdução}

A região do Nordeste brasileiro (NEB) tem como particularidade grande irregularidade na precipitação, sendo seu comportamento decorrente de um conjunto de fatores, bem como: suas características fisiográficas onde são influenciados por vários sistemas atmosféricos, fenômenos estes transientes. Esses fenômenos são definidos e caracterizados pela grande variabilidade espacial e temporal das chuvas na região, tornando-se um fator danoso às localidades atingidas, pois tanto podem provocar enchentes, como também secas, (ARAÚJO et al. 2008).

Compreender que a precipitação pluviométrica no NEB é decorrente do acoplamento de diversos sistemas atmosféricos em várias escalas com certa periodicidade, que podem ser alterados pelas características fisiográficas da região e por anomalias atmosféricas de escala planetária. Destacando-se o dipolo do Atlântico e o ENOS, que transformam a frequência de distribuição espacial e a intensidade desses sistemas; assim, é fundamental estudar a variabilidade interanual, com destaque na quadra chuvosa da região (DA SILVA et al. 2009).

Desta forma, vale ressaltar a Paraíba como o Estado do Nordeste que destaca-se por ter uma das maiores variabilidades espacial nas precipitações, sendo que o município de Cabaceiras, situado na microrregião do Cariri oriental paraibano, acumula uma média anual em torno de $300 \mathrm{~mm}$, enquanto isso na faixa litorânea, distante aproximadamente $200 \mathrm{~km}$, o total médio anual de precipitação é superior a 1500 mm (ARAÚJO et al. 2003).

Sabe-se que a previsão e o monitoramento de eventos meteorológicos caracterizados como extremos são de suma importância para os projetos de abastecimento de água, geração de energia elétrica e também de atividades agrícolas. Assim, com o monitoramento dos períodos secos e períodos úmidos é provável obter conhecimentos no tempo e espaço de características como, intensidade, duração e severidade de sistemas atmosféricos, podendo assim, adotar medidas preventivas em curto prazo, para diminuir impactos causados por fenômenos severos como secas e enchentes, (SANTOS et al. 2011).

É notório que o fornecimento de água das cidades é, em sua predominância, depende diretamente do escoamento dos rios, ou indiretamente do volume acumulado nas barragens; boa parte das culturas agrícolas depende unicamente da regularidade das chuvas e a probabilidade de uso de água subterrânea é considerada pequena quando comparada ao da água superficial (FREITAS, 2005).

Para melhor entender o comportamento climático, nas últimas décadas têm ocorrido grandes avanços, com isso vem aprimorando a resolução temporal e espacial das análises 
climáticas nas diferentes áreas do planeta terra, porém, a muito por saber e ainda existem extensas áreas que não dispõem de banco de dados satisfatórias sobre o comportamento dos elementos climáticos (MANOSSO et al. 2013).

Vale salientar a importância do clima como um fator que é determinado por uma combinação de fatores que vem pelas condições de comportamento atmosférico em escala de magnitude global, regional e local, assim podem também influenciar nas condições de relevo, posição continental e latitude (MANOSSO et al. 2013).

Assim, o presente trabalho tem como objetivo principal analisar a variabilidade climática da microrregião do Cariri Oriental Paraibano, através da climatologia espaçotemporal da precipitação e utilização do Índice de Anomalia de Chuva (IAC).

\section{Material e Métodos}

A área de estudo é a microrregião do Cariri Oriental localizada no Estado da Paraíba (Figura 1), constituída pelos municípios de Alcantil, Barra de Santana, Barra de São Miguel, Boqueirão, Cabaceiras, Caraúbas, Caturité, Gurjão, Riacho de Santo Antônio, Santo André, São Domingos do Cariri e São João do Cariri (Figura 2). De acordo com censo do (IBGE 2015) a microrregião possui uma área de $4.219,150 \mathrm{~km}^{2}$, com a população estimada de 63.704 habitantes (IBGE 2010).

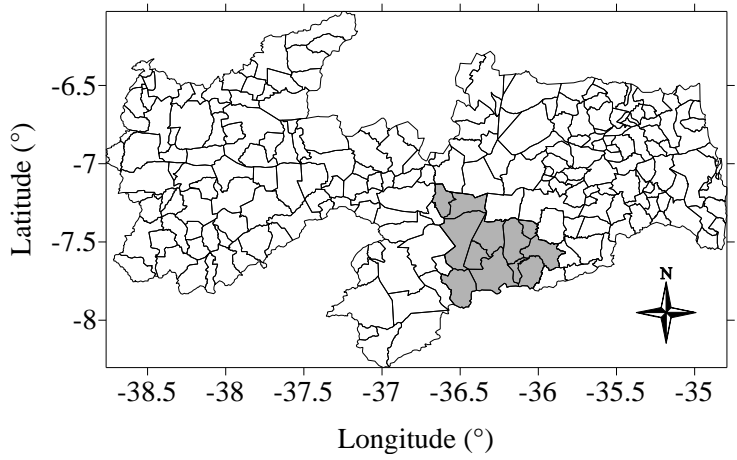

Figura 1. Localização da microrregião do Cariri Oriental Paraibano. Fonte: elaborado pelo primeiro autor.

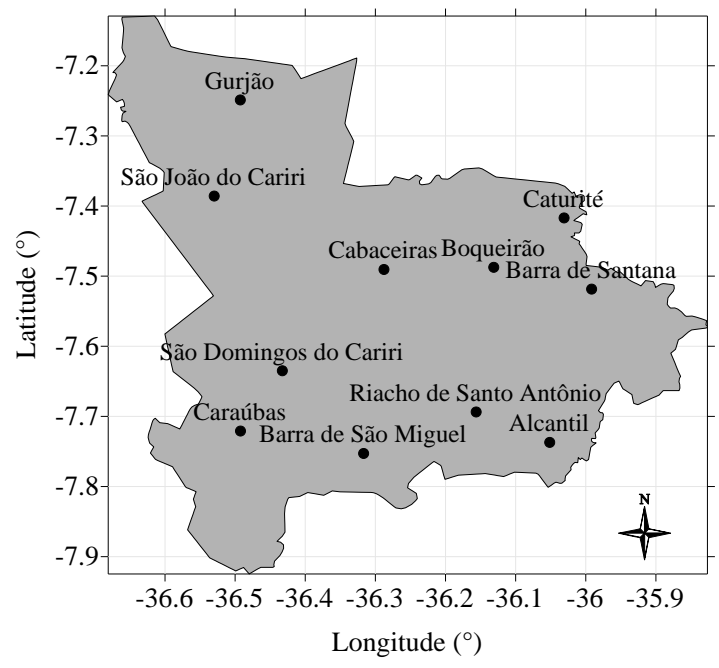

Figura 2. Localização das sedes dos municípios da microrregião de Cariri Oriental Paraibano. Fonte: elaborado pelo primeiro autor. 
Os dados pluviométricos foram fornecidos pela AESA (Agência Executiva de Gestão das Águas do Estado da Paraíba) e utilizados para o cálculo do Índice de Anomalia de Chuva (IAC) adaptado por Freitas (2005) e readaptado por Araújo et al. (2009). De forma similar os dados também foram utilizados para a confecção da variabilidade climática espaço-temporal do Cariri Oriental.

A avaliação do grau de severidade e duração dos períodos secos e úmidos será feita por meio do cálculo do IAC, (FREITAS, 2004 e 2005), obtido a partir das equações:

$$
\begin{array}{ll}
\mathrm{IAC}=3\left[\frac{(N-\bar{N})}{(\bar{M}-\bar{N})}\right] & \text { Para anomalias positivas: } \\
\mathrm{IAC}=-3\left[\frac{(N-\bar{N})}{(\bar{X}-\bar{N})}\right] & \text { Para anomalias negativas: }
\end{array}
$$

Em que:

$\mathrm{N}=$ precipitação mensal atual $(\mathrm{mm})$;

$\bar{N}=$ precipitação média mensal da série histórica $(\mathrm{mm})$;

$\bar{M}=$ média das dez maiores precipitações mensal da série histórica (mm);

$\bar{X}=$ média das dez menores precipitações mensais da série histórica (mm).

Os dados foram obtidos de 11 (onze) postos pluviométricos distribuídos na microrregião de Cariri Oriental, dos quais foi disponibilizada uma série histórica de 21 anos. Do ponto de vista climatológico, uma série como esta é considerada bastante curta, no entanto, de acordo com Santos et al. (2011), admite-se formular hipóteses sobre tendências de aumento ou redução das chuvas em condições atmosféricas extremas.

Conforme os mesmos autores, para a aplicação do IAC é recomendável à utilização de séries históricas com pelo menos 30 anos de dados e caso a série em questão tenha menos de 30 anos de dados, faz-se necessária uma adaptação através da qual a quantidade de médias utilizadas para o cálculo do IAC deve ser modificada de maneira a se tornar proporcional à quantidade de dados disponíveis; assim, deve- se calcular, em uma série de 21 anos de dados, por exemplo, as médias das 7 maiores ou 7 menores precipitações totais do período analisado. Depois de efetivado o cálculo do IAC, os valores gerados serão classificados de acordo com sua intensidade (Tabela 1). 
Tabela 1. Classes de intensidades do índice de anomalia de chuva (IAC) da Microrregião do Cariri Oriental Paraibano. Fonte: Araújo et al. (2009)

\begin{tabular}{ccc}
\hline & FAIXA DO IAC & CLASSES DE INTENSIDADE \\
\hline De 4 acima & Extremamente úmido \\
Índice & 2 a 4 & Muito úmido \\
De anomalia & 0 a 2 & Úmido \\
De chuva & 0 a -2 & Seco \\
(IAC) & -2 a -4 & Muito seco \\
& De -4 abaixo & Extremamente seco \\
\hline
\end{tabular}

Para análise da hipsometria (relevo) e da declividade foram utilizadas imagens SRTM (Shuttle Radar Topography Mission) com resolução espacial de 30x30m, disponibilizadas gratuitamente no site da Earth Explore (https://earthexplorer.usgs.gov) administrado pelo Serviço Geológico dos Estados Unidos (U.S.G.S. - United States of Geological Survey). Os referidos mapas foram elaborados utilizando o Sistema de Informação Geográfica ArcGis for Desktop Advanced (formerly ArcInfo) for Home Use Licence - versão 10.4.1. Foi utilizada a ferramenta Spatial Analyst tools. O mapa hipsométrico foi confeccionado com base no MDT e dividido em 12 classes altimétricas, segundo o método de "quebras naturais" (natural breaks) onde a distribuição do conjunto de classes maximiza a diferença entre as classes e identifica pontos de quebra que melhor agrupem valores similares.

O mapa de declividade foi elaborado a partir da imagem SRTM com os valores de declividade em porcentagem. Foram estabelecidas 6 classes de declividade descriminadas na tabela 2 (EMBRAPA, 1979; 2004).

Tabela 2. Classes de declividade em valores percentuais. Fonte: EMBRAPA (1979, p.27)

\begin{tabular}{cc} 
Declividade $(\%)$ & Classes \\
\hline $0-3$ & Plano \\
$3-8$ & Suave ondulado \\
$8-20$ & Ondulado \\
$20-45$ & Fortemente ondulado \\
$45-75$ & Montanhoso \\
$>75$ & Escarpado \\
\hline
\end{tabular}

\section{Resultados e Discussão}

A partir da análise hipsométrica (Figura 3) e da declividade (Figura 4) da Microrregião do Cariri Oriental, observa-se uma mudança gradual de um patamar de aplainamento para outro 
demonstrando uma área denudacional com declives suaves, característica dos pedimentos elaborados no ambiente semiárido. A Figura 3 demonstra que a área possui altitudes que vão de 188 a 802 m, sendo as áreas mais baixas próximos aos cursos dos rios, aumentando gradualmente em direção as suas extremidades, tanto no sentido Norte/Noroeste quanto Sul/Sudoeste chegando a valores superiores a $800 \mathrm{~m}$.

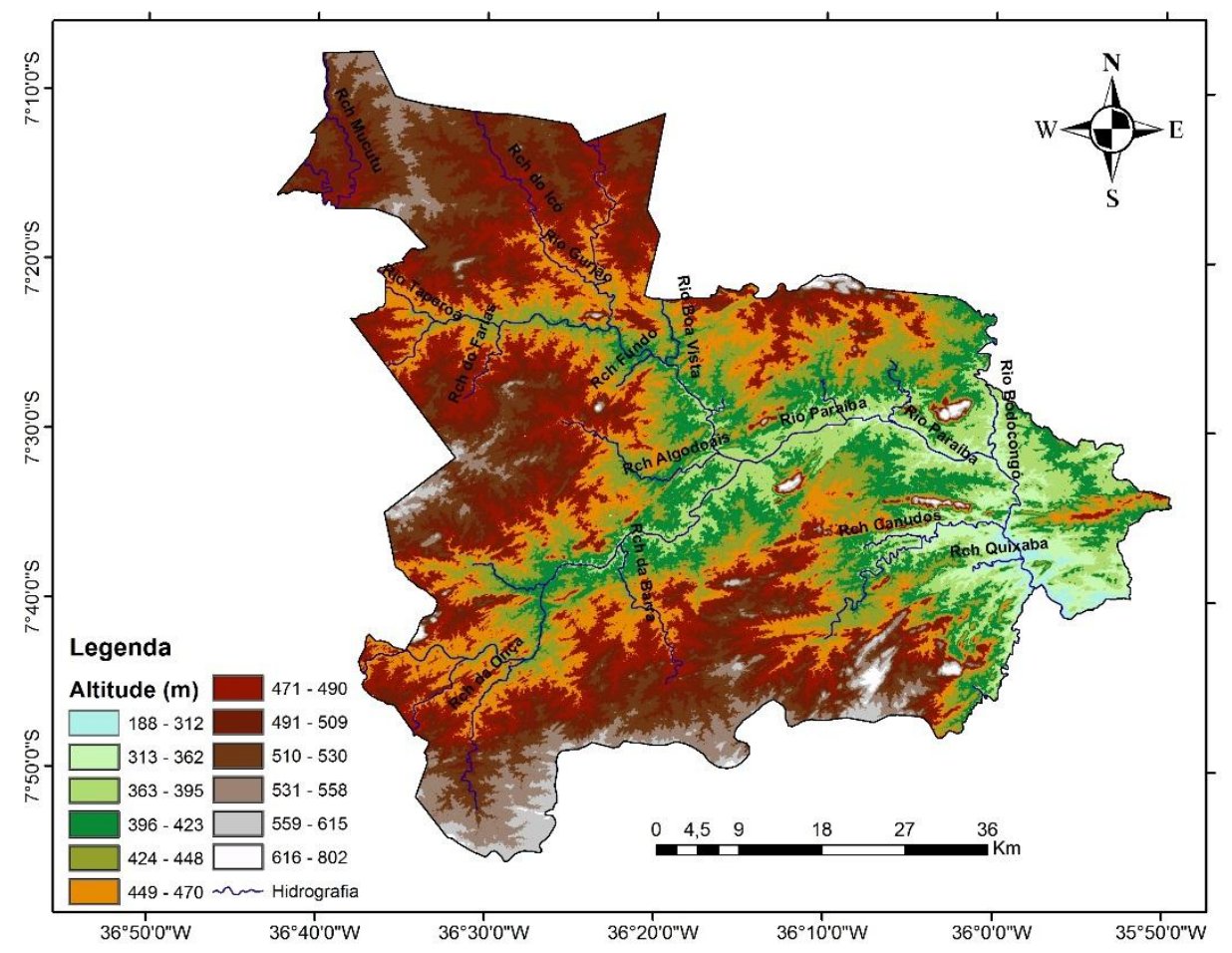

Figura 3. Hipsometria do Cariri Oriental, Paraíba-PB, Brasil. Fonte: elaborado pelo quarto autor.

A declividade caracteriza-se, predominantemente como suave ondulada a ondulada. As áreas de maior declividade são representadas pela classe montanhoso ocorrendo nas vertentes das principais serras e dos inselbergs da região. 


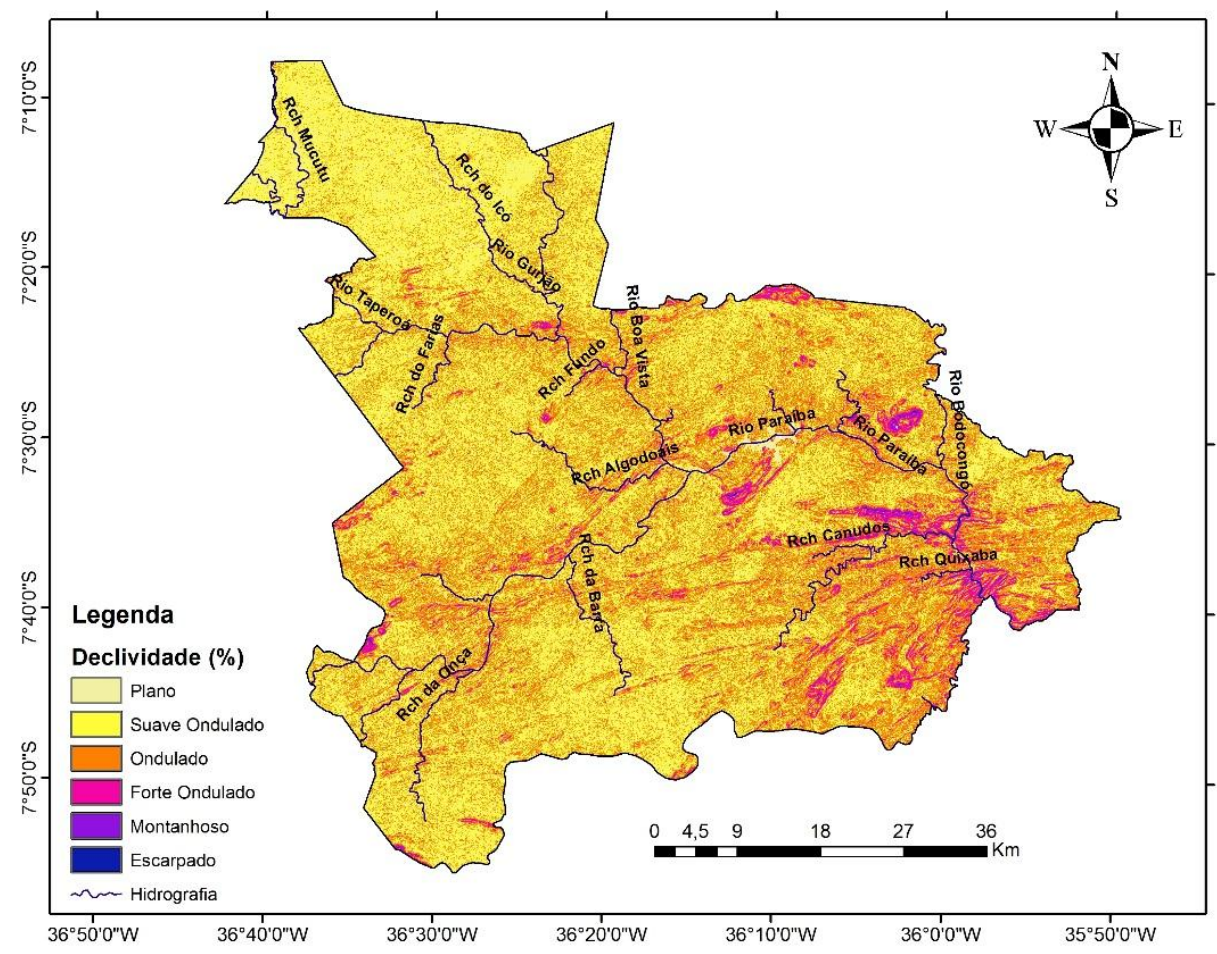

Figura 4. Declividade do Cariri Oriental, Paraíba-PB, Brasil. Fonte: elaborado pelo quarto autor.

Apresenta-se na Figura 5 a climatologia temporal da precipitação da microrregião do Cariri Oriental, mostra-se que, a média mensal de precipitação da microrregião é de aproximadamente $38,0 \mathrm{~mm}$, e que seu período chuvoso tem inicio no mês de janeiro e término no mês de julho, com sete meses acima da média mensal, sendo o mês de março o mês mais significativo com a média $76,3 \mathrm{~mm}$, tal transição é ocasionada por causa da atuação mais evidente da Zona de Convergência Intertropical, que atua de fevereiro a maio gerando uma maior precipitação nos meses de março (UVO, 1989). Em contrapartida o período seco ocorre entre os meses de agosto a dezembro, tendo setembro como o mês mais seco, com média 6,9 $\mathrm{mm}$. 


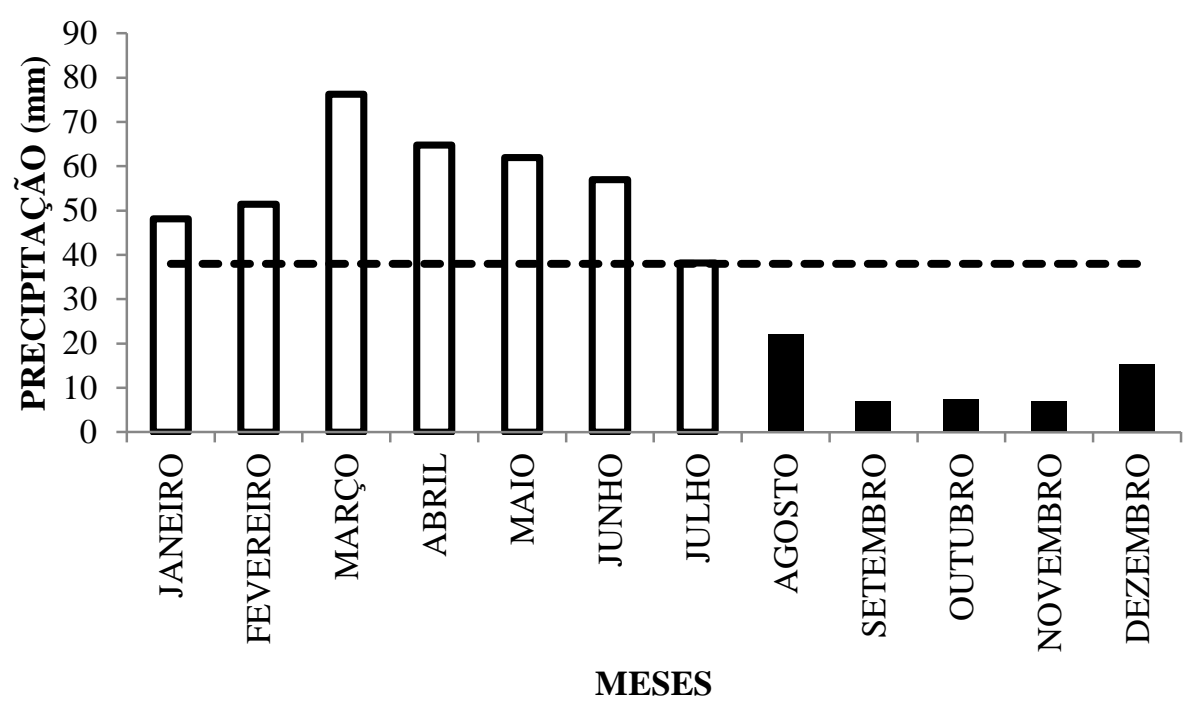

Figura 5. Precipitação mensal da microrregião do Cariri Oriental Paraibano. Fonte: elaborado pelo primeiro autor.

A Figura 6 apresenta o comportamento da precipitação da microrregião do Cariri Oriental Paraibano em forma de porcentagem, que é uma ferramenta de suma importância para avaliar a distribuição da precipitação da localidade, comparando com a (Figura 3) mostrar-se que a 7 (sete) meses úmido e 5 (cinco) meses secos, diante disso, o período chuvoso apresentar $83 \%$ da precipitação, seguindo o período seco com $17 \%$ da precipitação.

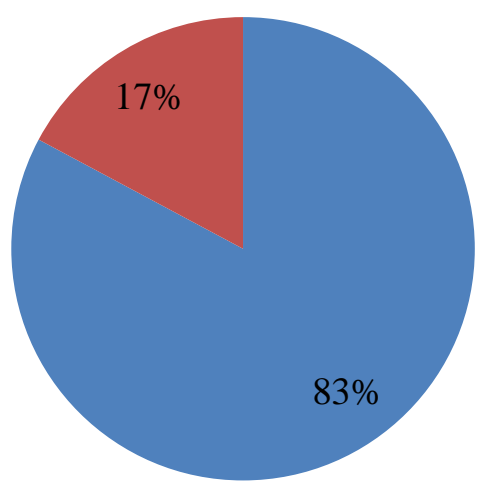

\section{- MÉDIA DO PERÍODO CHUVOSO} - MÉDIA DO PERÍODO SECO

Figura 6. Representação percentual da precipitação da microrregião do Cariri Oriental Paraibano. Fonte: elaborado pelo primeiro autor.

A climatologia acumulada da microrregião do Cariri Oriental Paraibano é demonstrada na Figura 7, na qual evidencia-se a variação de 300 a 600 milímetros por ano distribuídos em toda a área de estudo. Vale ser ressaltado também que valores acima de $500 \mathrm{~mm}$ são observados 
nos setores Norte e Leste da microrregião, decrescendo nos setores Sul e Oeste, com valores abaixo de $450 \mathrm{~mm}$.

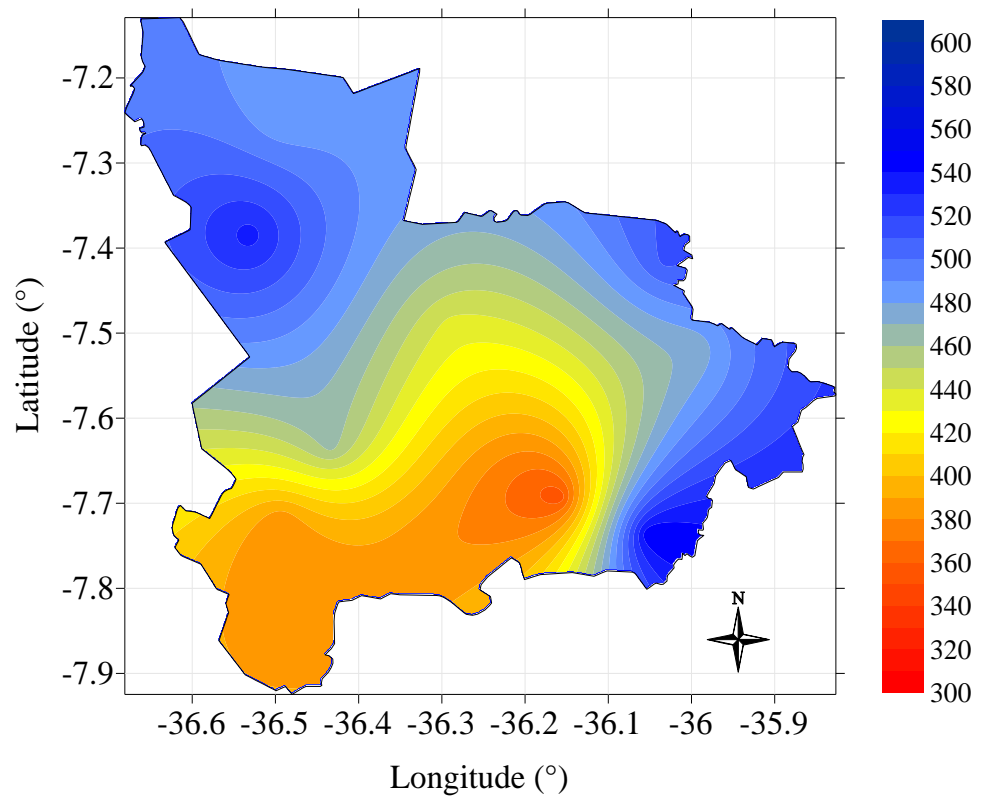

Figura 7. Distribuição espacial da precipitação acumulada da microrregião do Cariri Oriental Paraibano. Fonte: elaborado pelo primeiro autor.

No intuito de melhor entender o comportamento dinâmico da precipitação analisou-se a espacialização da precipitação da microrregião Cariri Oriental mensalmente, Figura 8 (A) a 8 ( L).

Nas Isoietas médias mensais da microrregião Cariri Oriental foi ilustrado o comportamento da precipitação de janeiro a dezembro, na qual o mês de janeiro (Figura $8 \mathrm{~A}$ ) inicia-se a estação chuvosa na microrregião do Cariri Oriental Paraibano, com valores máximos de precipitação acima de 57,4 mm entre as regiões leste e oeste, os valores mínimos de precipitação consistir abaixo de 51,6 mm que apresentaram-se concentração nas regiões Norte e Sul. Para fevereiro (Figura 8 B) evidencia-se uma distribuição bem mais abrangente com valores máximos de precipitação acima de $60,5 \mathrm{~mm}$, entre a região Oeste parte da região Norte, e com valores mínimos de precipitação na região Leste, Sul e parte da região Norte estando abaixo de 52,1 $\mathrm{mm}$.

Para março (Figura $8 \mathrm{C}$ ), mês esse que ocorre o ápice da estação chuvosa, de acordo com a Figura 5, mês de extrema importância para microrregião do Cariri Oriental Paraibano devido à precipitação ser acima da média do período, no qual, todo volume precipitado dá suporte, direto ou/e indiretamente, a agricultura, a fauna e a flora local, ressaltando o abastecimento dos mananciais, açudes e lagoas da área estudada; o mês em questão, destacou- 
se com valores de precipitação entre $63,4 \mathrm{~mm}$ a $94,9 \mathrm{~mm}$, onde encontra-se maiores valores de precipitação entre a região Oeste e em partes das regiões Norte e Sul, seus menores valores de precipitação entre a região leste e em partes nas regiões Norte e Sul. Segundo Araújo et al. (2009) o mês de março, é mais hábil em termos de precipitação pelo fato da atuação da Zona de Convergência Intertropical (ZCIT) que alcança seu máximo neste mês, propiciando realmente um acúmulo considerável na região, e consequentemente uma melhor adequação da área de estudo.

Em contrapartida o mês de abril (Figura 8 D) apresentou-se similaridades com mês de março, entretanto, seus maiores valores de precipitação acima de $60,9 \mathrm{~mm}$, entre parte da área da região Norte e da região Oeste e Leste e menores valores de precipitação abaixo 58,2 mm, em parte da área da região Sul e Norte. O mês de maio (Figura 8 E) mostra-se com valores máximos de precipitação acima de $62,8 \mathrm{~mm}$ em partes da área da região Norte, Oeste e Leste e menores valores de precipitação abaixo de 58,6 mm entre partes da área da região Norte e Sul. O mês junho (Figura 8 F) revelar-se com seus valores máximos de precipitação acima de 64,1 mm, entre partes da área das regiões Norte, Leste, e menores valores de precipitação abaixo de $58,1 \mathrm{~mm}$, entre as partes da área das regiões Norte, Oeste e Sul.

O término da estação chuvosa é no final do mês de julho (Figura $8 \mathrm{G}$ ), tendo em vista seus valores máximos de precipitação acima de $52,3 \mathrm{~mm}$, em pequenas áreas da região Norte e menores valores precipitação, sendo abaixo de 51,5 mm, entre regiões Sul, Oeste, Leste e em partes da área da região Norte. O mês de agosto (Figura 8 H) é de suma importância, pois iniciase a estação seca na microrregião de Cariri Oriental Paraibano, onde seus valores máximos de precipitação acima de 34,1 mm são evidenciados em partes das áreas das regiões Norte, Leste e os valores mínimos de precipitação, abaixo de $29,8 \mathrm{~mm}$, entre as regiões Oeste, Sul e partes da região Norte.

Os meses de setembro (Figura $8 \mathrm{I}$ ), outubro (Figura $8 \mathrm{~J}$ ) e novembro (Figura $8 \mathrm{~K}$ ) apresentaram valores mínimos de precipitação abaixo de $15 \mathrm{~mm}$, distribuído por toda área da microrregião do Cariri Oriental. Tal fato corrobora com as afirmações de Freitas (2005) que afirma que as secas são avaliadas como um fenômeno natural que se distinguem claramente das demais catástrofes naturais. Assim, pode-se então afirma que em meses com baixo índice de precipitação é considerado fenômeno natural.

E por fim, o mês de dezembro (Figura $8 \mathrm{~L}$ ) diferencia-se dos meses de setembro (Figura $8 \mathrm{I}$ ), outubro (Figura $8 \mathrm{~J}$ ) e novembro (Figura $8 \mathrm{k}$ ), pois obteve valores máximos acima de 15,4 mm de precipitação entre as regiões Oeste, Sul uma parte da área região Norte, e valores 
mínimos de precipitação abaixo de 15,4 mm em uma parcela da área da região Norte e na região leste, tendo em vista que mês que marca fim da estação seca.

(A)

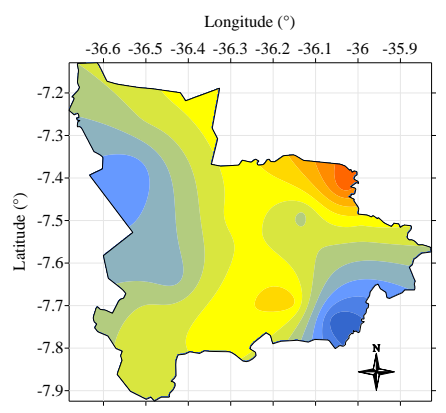

(D)

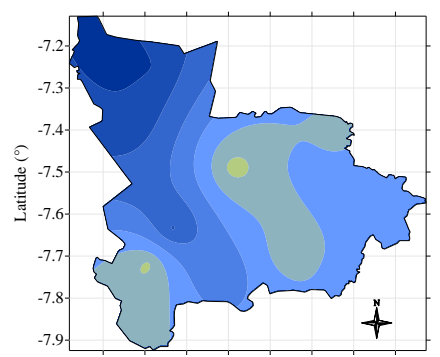

(G)

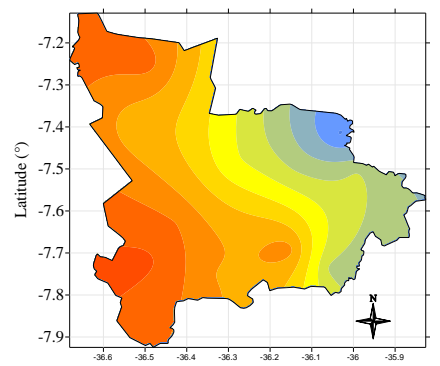

(J)

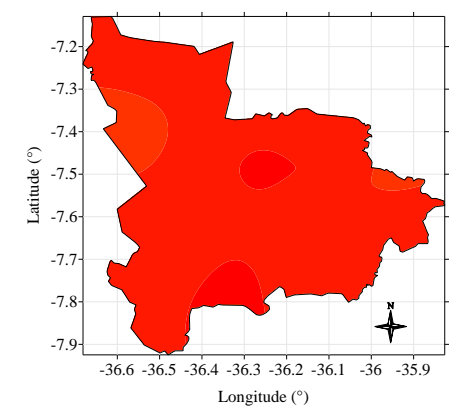

(B)

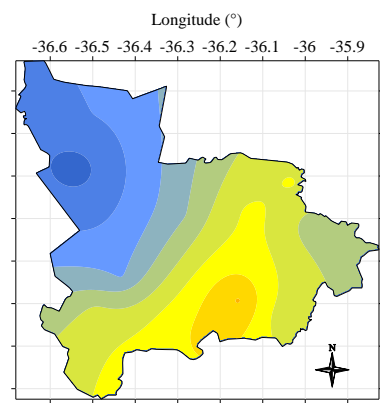

(E)

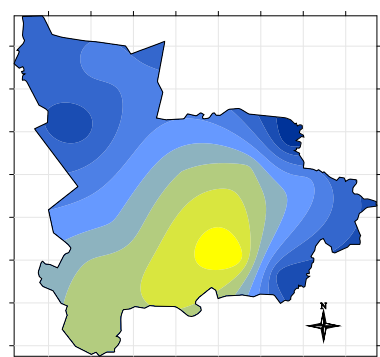

$(\mathrm{H})$

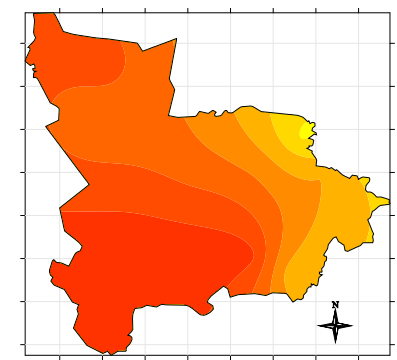

$(\mathrm{K})$

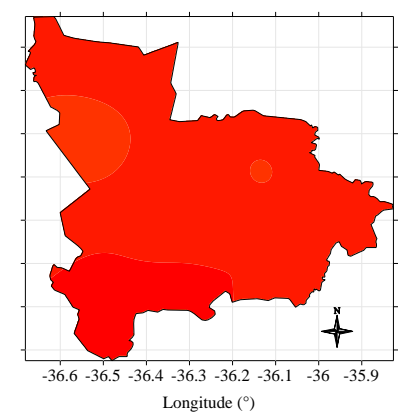

(C)

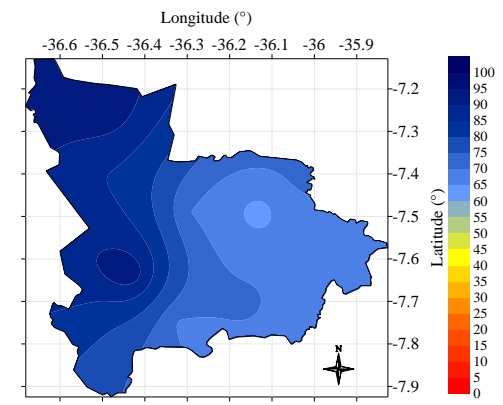

(F)

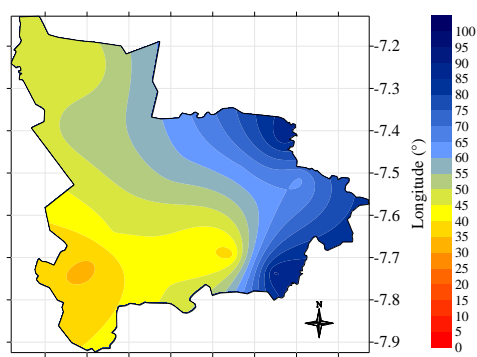

(I)

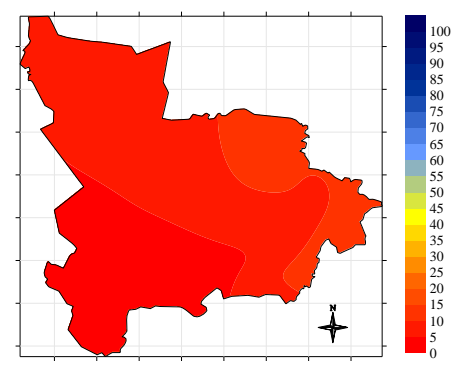

(L)

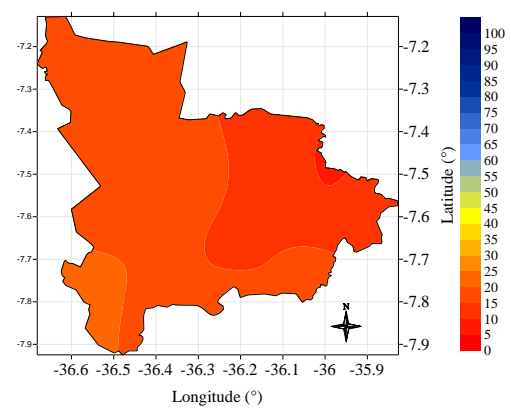

Figura 8. Isoietas médias mensais da Microrregião do Cariri Oriental Paraibano, Janeiro (A), Fevereiro (B), Março (c), Abril (B), Maio (E), Junho (F), Julho (G), Agosto (H), Setembro (I), Outubro (J), Novembro (K), Dezembro (L). Fonte: elaborado pelo primeiro autor. 
Para melhor estimar a variabilidade espacial da precipitação empregou-se o Índice de Anomalia de Chuva (IAC), Figura 9, no intuito de melhor identificar a intensidade e duração dos períodos secos e úmidos para série histórica da precipitação, no qual os anos da série histórica foram definidos em nove anos chuvosos, de acordo com a Tabela 1, nos quais foram classificados como anos ÚMIDOS os anos de 1994, 2002, 2005 e 2010; MUITO ÚMIDOS os anos de 2000, 2008 e 2009; e EXTREMAMENTE ÚMIDO os anos de 2004 e 2011. Ainda de acordo com a mesma tabela, foram definidos doze anos secos, classificados como anos SECOS os anos de 1995, 1996, 1997, 2001, 2006, 2007 e 2014; MUITO SECO os anos de 1999, 2003 e 2013; e EXTREMAMENTE SECO os anos de 1998 e 2012.

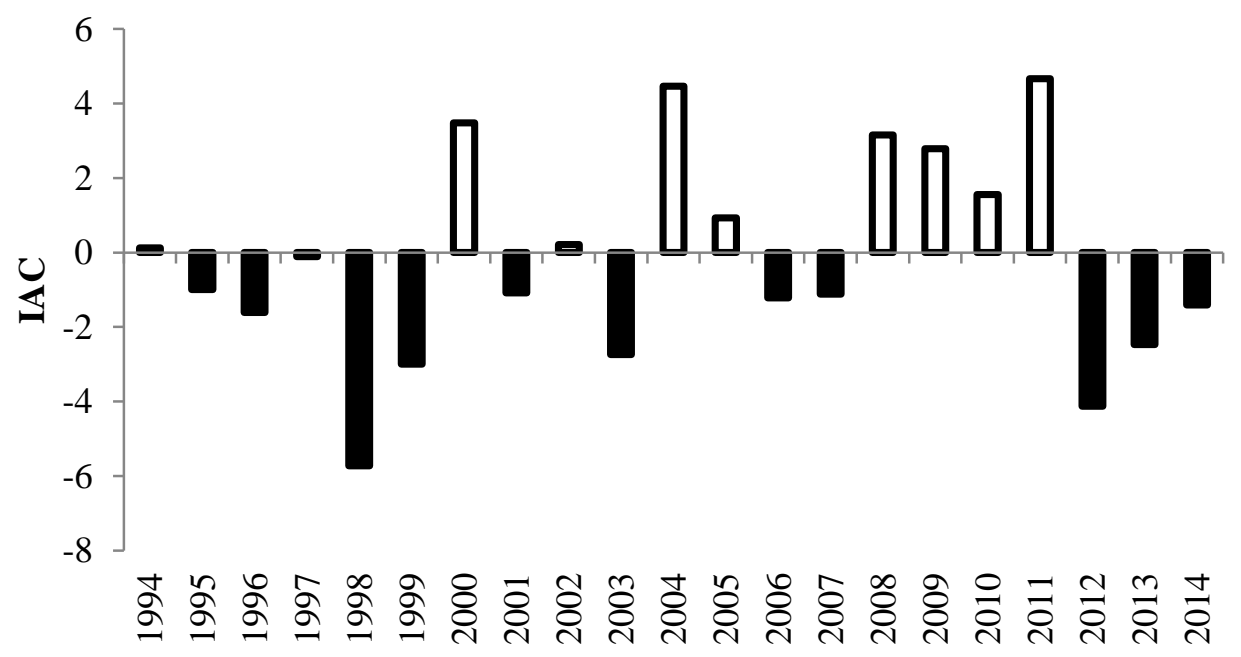

ANOS

Figura 9. Índice de Anomalia de Chuva a microrregião do Cariri Oriental. Fonte: elaborado pelo primeiro autor.

Diante dos resultados pode-se ressaltar que em períodos úmidos problemas podem ocasionar enchentes nas cidades por falta de infraestrutura, prejuízos na agricultura dentre outras peculiaridades e aos períodos secos podem estar associados a grande dificuldade com a escassez de água, ocasionando a seca, prejuízo também na agricultura, por falta de chuvas e na criação de animal, como outras interações danosas ao meio. Mas, vale também ser ressaltada que em séries pequenas ou grandes de precipitação, o importante é a alternância de períodos chuvosos e secos, pois assim se observará um equilíbrio ecológico entre a fauna, flora e o homem, sem prejudicar as atividades e sua dinâmica natural de interação do homem com a natureza. 
Para melhor entender o comportamento desse índice, avaliou-se o seu comportamento intra-anualmente, entre dois representantes secos (Figura 10) e dois chuvosos, no qual foi ressaltado também a sua variação dentro da estação seca e chuvosa dos anos analisados.

Os anos representados como Secos foram os anos de 1998 e 2012, no qual obtiveram IAC negativo e os anos representados como Chuvosos, foram os anos de 2004 e 2011 que apresentam IAC positivo (Figura 9). Com isso, o ano de 1998 foi classificado como Extremamente Seco, e considerando a variabilidade temporal (Figura 5) na qual demonstrou que estação chuvosa ocorre de janeiro a julho e a estação seca de agosto a dezembro, observase que no ano 1998 apenas os meses de janeiro e fevereiro não seguiu a variabilidade climática dentro da estação chuvosa, ou seja, meses com chuvas abaixo do esperado; já na estação seca, o mês de agosto se diferenciou da variabilidade climática pelo fato do mês ter apresentado seu IAC positivo, ou seja, foi um mês chuvoso dentro da estação seca. De forma similar, o ano de 2012, o qual foi classificado também como Extremamente Seco, evidenciou que os meses de março e abril, que estão dentro da estação chuvosa, apresentaram IAC negativos, ou seja, foram meses com chuvas abaixo do esperado; e a estação seca seguiu a variabilidade temporal em sua normalidade, com cinco meses secos (agosto a dezembro) com IAC negativos.

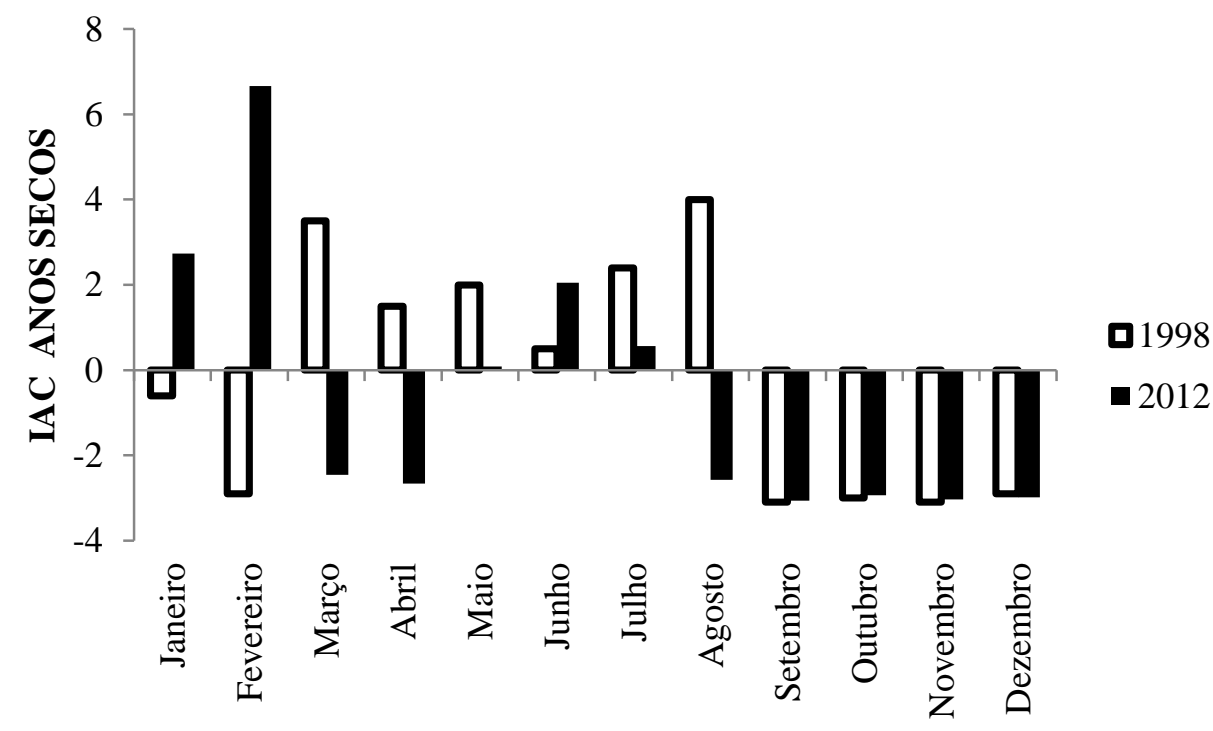

Figura 10. Índice de anomalia de chuva (IAC) dos anos secos da microrregião do Cariri Oriental. Fonte: elaborado pelo primeiro autor.

Para os anos chuvosos de 2004 e 2011 (Figura 11), observa-se que o ano de 2004 foi classificado em Extremamente Úmido, neste ano os meses de março, abril e maio não seguem a variabilidade temporal visto na Figura 3, apresentando IAC negativos, ou seja, meses com chuvas abaixo da média esperada dentro da estação chuvosa; e os meses de agosto a dezembro 
aprestaram IAC negativos, seguindo a variabilidade temporal esperado da estação seca da região estudada. Já o ano de 2011 foi também classificado como ano Extremamente Úmido, neste ano o mês de junho obteve IAC negativo, ou seja, foi um mês dentro da estação chuvosa com poucas chuvas; e os demais meses seguem a variabilidade climática estação seca, com chuvas abaixo da média em toda área estudada.

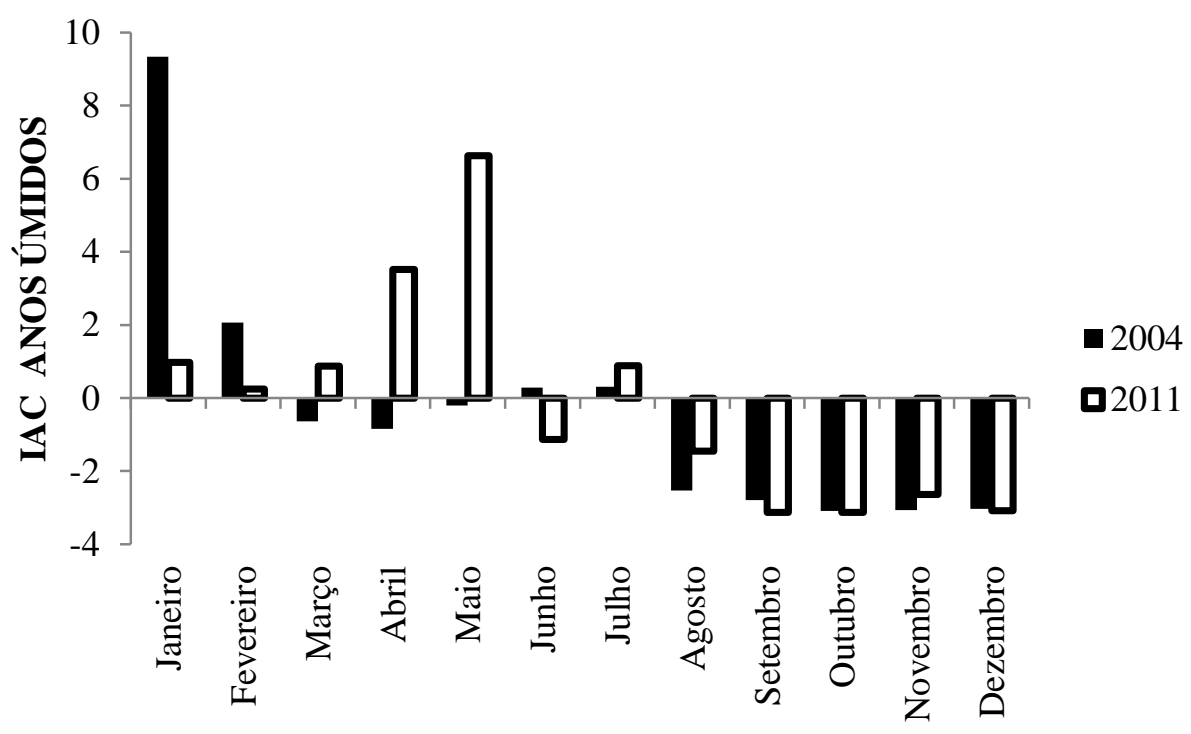

Figura 11. Índice de anomalia de chuva (IAC) mensal de anos úmidos da microrregião do Cariri Oriental. Fonte: elaborado pelo primeiro autor.

\section{Considerações Finais}

Conclui-se que a climatologia temporal da precipitação da microrregião do Cariri Oriental Paraibano apresentou início do período chuvoso no mês de janeiro e término no mês de julho, com sete meses considerados úmidos, sendo o mês de março o mais significativo em quantidade e intensidade de precipitação. Em contrapartida, o período seco ocorre entre os meses de agosto a dezembro, tendo setembro como o mês mais seco.

A climatologia espacial da precipitação da microrregião do Cariri Oriental Paraibano demonstrou que a maior precipitação concentra-se nos setores Norte e Leste; e menor distribuição espacial de precipitação nos setores Sul e Oeste. Ainda em relação à espacialização da precipitação, evidenciou-se a intensa e abrangente distribuição da precipitação nos meses do período chuvoso, a exemplo de março; e diminuição significativa no período seco em toda área estudada nos meses de setembro, outubro e novembro. 
Conclui-se também que o Índice de Anomalia de Chuva é uma ferramenta de importância significativa em áreas de vulnerabilidade ambiental, validando que a alternância de períodos chuvosos e secos é o que realmente importa, pois só assim se observará um equilíbrio ecológico em flora, fauna e o homem.

Por fim, vale ser ressaltado a importância deste trabalho na área da ecologia, pois através desses resultados pode-se estabelecer padrões que constituem períodos distintos de abundância e escassez de água para as atividades humanas e para dinâmica ambiental, gerando informações aos gestores e órgãos competentes de melhor adequação do meio para os diversos fins.

\section{Referências Bibliográficas}

AMORIM, R. F.; SILVA, F. M.; CORRÊA, A. C. B.; SILVA, D. G. Comportamento Sazonal e Espacial da Precipitação na Microbacia Riacho Passagem/RN por Técnicas de Séries Temporais e Probabilística. Revista Brasileira de Climatologia. Ano 11 - Vol. 16 - JAN/JUL 2015 .

ARAÚJO, L. E.; BECKER, C. T.; PONTES, A. L. Periodicidade da precipitação pluviométrica no estado da Paraíba. In: XIII CONGRESSO BRASILEIRO DE AGROMETEOROLOGIA, 2003, Rio Grande do Sul. Anais II. Santa Maria: RS, 2003. p. $947-948$.

ARAÚJO, L. E.; SOUSA, F. DE A.S; RIBEIRO, M. A. DE F. M; SANTOS, A. S; MEDEIROS, P. S. Análise Estatística de Chuvas Intensas na Bacia Hidrográfica do Rio Paraíba. Revista Brasileira de Meteorologia, v.23, n.2, 162-169, 2008.

ARAÚJO, L. E.; MORAES NETO, J. M. DE; SOUSA, F. DE A. S. Classificação da precipitação e da quadra chuvosa da Bacia do Rio Paraíba utilizando índice de anomalia de chuva (IAC). Ambi-Agua, v.4, p.93-110, 2009.

DA SILVA, D. F; SOUSA, F. A. S; KAYANO, M.T; GALVÍNCIO, J. D. Influência da Variabilidade Climática Global e de suas Escalas Temporais sobre a Precipitação no Alto Mundaú (PE). RBGF- Revista Brasileira de Geografia Física Recife-PE, Vol.2, n.03, setdez, 2009, 64-82.

EMPRESA BRASILEIRA DE PESQUISA AGROPECUÁRIA - EMBRAPA. Serviço Nacional de Levantamento e Conservação de Solos (Rio de Janeiro, RJ). Súmula da 10. Reunião Técnica de Levantamento de Solos. Rio de Janeiro:1979. 83p. (Embrapa-SNLCS. Micelânea, $1)$.

FREITAS, M. A. S. A Previsão de secas e a gestão hidroenergética: o caso da Bacia do Rio Parnaíba no nordeste do Brasil. In: SEMINÁRIO INTERNACIONAL SOBRE REPRESAS Y OPERACIÓN DE EMBALSES, 2004, Puerto Iguazú. Anais... Puerto Iguazú: CACIER, 2004. v. 1. p. 1-1. 
FREITAS, M. A. S. Um sistema de suporte à decisão para o monitoramento de secas meteorológicas em regiões semi-áridas. Revista Tecnologia, Fortaleza, v. suplem., p. 84-95, 2005.

IBGE 2010- Instituto Brasileiro de Geografia e Estatística. Contagem da população 2010. Disponível em: < http://cidades.ibge.gov.br/xtras/perfil. php?lang=\&codmun=250053> . Acessado em 27 de maio de 2014.

IBGE 2015- Instituto Brasileiro de Geografia e Estatística. Disponível em: < http://cidades.ibge.gov.br/xtras/perfil. php?lang=\&codmun=250053>. Acessado em 1 de maio de 2017.

MANOSSO, F. C.; GOMES, M. F.; AOKI, A.; MANOSSO, D. C. C. Distribuição Espacial e Temporal da Precipitação e Temperatura Média na Região da Serra do Cadeado (PR). Revista Brasileira de Climatologia. Ano 9-Vol. 12 - JAN/JUL 2013.

SANTOS; P. E.; CORREIA, M. F.; ARAGÃO; M. R. S.; SILVA, F. D. DOS S. Eventos Extremos de Chuva e Alterações no Regime Hidrológico da Bacia Hidrográfica do Rio São Francisco: Uma Aplicação do Índice Rai (RAINFALL ANOMALY INDEX). Engenharia Ambiental - Espírito Santo do Pinhal, v. 8, n. 2, p. 315-330, abr. /jun. 2011.

UVO, C. R. B. A zona de convergência intertropical (ZCIT) e sua relação com na região norte e nordeste brasileiro. Dissertação de mestrado. INPE. São José dos campos, 1989.

\section{Agradecimentos}

Agradeço a minha família que foi minha fortaleza nos momentos a que cair, onde sempre estenderam a mão para me levantar e enxugar minhas lagrimas em especial minha mãe Marinalva Maria. Meu orientador Lincoln Eloi que foi um mestre, amigo e pai nesses três anos e meio, tendo um papel muito importante no meu desenvolvimento acadêmico, na orientação do meu TCC e dando conselhos qual o caminho certo a seguir e que nunca desistisse dos meus sonhos.

Recebido em: 03/04/2018

Aceito para publicação em: 19/04/2018 